\section{Mosquitoes in Britain}

The British Mosquito Control Institute at Hayling Island, Hants, has recently issued at the price of $1 s$. a useful pamphlet. entitled "The Morphology and Biology of Culex molestus: Observational Notes for Investigators". The object of this publication is to facilitate the investigation of cases in which mosquitoes are causing (or periodically cause) annoyance in dwelling-houses or other buildings, especially those in 'built-up' areas. 'From among thirty species of mosquito known in Britain, Culex molestus closely resembles our commonest mosquito, namely, $C$. pipiens, in many ways. It is, however, a fierce and persistent blood-sucker of man, whereas Culex pipiens rarely (if ever) bites human beings. The species molestus can lay eggs without having had a bloodmeal, although the number of eggs laid is much reduced. It breeds at all times of the year, and mating, unlike that of almost all other mosquitoes, can occur in a very confined space. So far as is known it breeds chiefly in accumulations of water in dark or semidark warm situations, but a good deal more needs to be found out on this subject and many other features regarding its habits. So far, Culex molestus has only been recognized in London, Harwich and Hull, but it needs to be known whether it has a wider distribution in the country. Anyone willing to help in this investigation can receive a free copy of the pamphlet nentioned on application to the Director of the Institute, Mr. J. F. Marshall, whose temporary address is "Wayside", 47 London Road, Cheltenham.

\section{Diets for Patients with Ulcers of the Stomach and Duodenum}

THE Ministry of Food, in collaboration with the Ministry of Health, has prepared a twelve-page pamphlet of diets for patients with ulcers of the stomach and duodenum. This pamphlet, which is not intended for the general public, since the dieting of cases of the above type is a matter for expert supervision, is approved by the Food Rationing (Special Diets) Advisory Committee of the Medical Research Council and will, it is hoped, help general practitioners, and others "professionally concerned with the feeding of such patients, to cope with difficulties of war-time food supplies. The pamphlet contains rules for feeding and planning diets, weekly menus and recipes for patients who have either recovered from the acute stage of peptic ulcer or from whom symptoms due to the ulcer have almost disappeared. In planning the menus, the aim has been to provide a reasonably varied diet based on the foods available under present conditions to these patients. Copies of the pamphlet may be obtained by those professionally concerned with the problem, on application to the Secretary (Public Relations Division), Ministry of Health, Whitehall, S.W.1.

\section{Incidence of Scarlet Fever}

According to the Weekly Epidemiological Record of March 2, in recent years scarlet fever has ceased to be a disease of any great clinical importance, but its geographical distribution is extraordinary as it is very frequent in northern latitudes and practically unknown in the torrid zone. In the seventies of the nineteenth century, its fatality in northern Europe was more than 10 per cent, and in mortality it exceeded any other acute infection. Between 1875 and 1885 the mortality was halved; it was halved again between 1885 and 1900 , and in the present century it has fallen below 1 per cent. Scarlet fever is endemic in all parts of the world in which it oceurs, but shows wide variation in incidence from year to year. During the present War, the incidence of this disease has shown no relationship to the public nutrition or the state of military activity, as is shown by the fact that in Germany, which is the best nourished country on the Continent and presents the greatest military activity, the incidence of scarlet fever is excessively high, as it is also in Norway, Holland and Greece, where the nutrition is low. In England and Wales, where the nutrition is good, incidence of the disease fell below normal until 1941, since when it has shown a slight increase. In the United States the numbers are, still falling. It is noteworthy that in no country where returns are available has there been any reported increase of severity.

\section{Substitutes for Structural Material in South Africa}

Mr. N. Stutterheim and Mr. J. Shaw, of the Investigation Section of the Building Control, South Africa, described some work carried out by the Section during the ten months of its existence at a meeting of the South African Society of Civil Engineers on March 15. They discussed particularly the investigation of substitutes for steel and timber for building purposes. The work is being carried out in the Civil Engineering Department, University of the Witwatersrand, under Prof. Bernard $H$. Knight, acting head of the Department. The most promising material examined, taking South African conditions of service and also the question of supplies into consideration, appears to be 'Sorel' cement with sawdust filler, reinforced with wood lathes. It can be sawn, nailed and screwed, and tends to expand and contract with varying moisture conditions much as timber does. Its chief economic recommendation is that it can be cast to any size or shape without the use of high temperature, high pressure or skilled labour. Some houses have been built in Johannesburg in which all timber has been replaced with 'Sorel' cement composition. A sawdust cement composition has also been developed by certain South African firms. Other research work carried out by the Investigation 'Section has been the testing of tiles and flooring materials; for testing the latter, a machine has been devised in the University of the Witwatersrand consisting of leather pads fed with crusher dust to simulate the abrasive effect of leather soles and dust.

\section{Properties of Paracon}

According to an article by B. S. Biggs (Bell Lab. Rec., 22, No. 7 ; March 1944), when the development of 'Paracon', a new synthetic rubber, was announced by the Bell Laboratories, its resistance to oil and heat and its low brittle point, lack of odour and fast curing cycle were emphasized. Not all these characteristics can be held at maximum values in every composition, but various combinations of them ean be obtained by selecting the intermediate compounds used in manufacture. This follows because the 'Paracons', in contrast with most elastic compounds, comprise a group of compounds rather than a single one. Chemically, the 'Paracons' are chain esters of high molecular weight. Among the substances that may be used are sebacic and succinic acids and ethylene and propylene glycols. These chemicals are obtainable from agricultural, coal and petroleum 